\title{
New insights on low-grade and T-cell lymphoma
}

\section{William Tse}

Address: University of Colorado Cancer Center, Denver, CO, USA

Email: William Tse - william.tse@uchsc.edu

from Current trends in leukemia, lymphoma and myeloma

White Plains, NY, USA. 31 January 2009

Published: 26 June 2009

Journal of Hematology \& Oncology 2009, 2(SuppI I):A3 doi:10.1 I86/I756-8722-2-SI-A3

This abstract is available from: http://www.jhoonline.org/content/2/SI/A3

(c) 2009 Tse; licensee BioMed Central Ltd.

The advances in low-grade lymphoma \& T-cell lymphoma from the 2008 ASH meeting were presented. These included therapeutic regimens for low grade lymphoma, frontline bendamustine plus rituximab data, radioimmunotherapy consolidation in advanced disease, idiotype vaccine, and other novel therapeutic agents such as next generation anti-CD20 GA101, syk inhibitor Fostamatinib in treatment of low-grade lymphoma. In T-cell lymphoma, updates were discussed on phase II HOVON 69 trial data of combination of alemtuzumab/CHOP, pralatrexate and romidepsin for relapsed/refractory PTCL, Lasparaginase-containing regimen for extranodal NK/T-cell lymphoma. 